\title{
Chronic Low Back Pain Frequency and its Risk Factors in Clinical and Office Staff of Hospitals
}

\author{
Seyedeh Negar Assadi ${ }^{1, *}$ \\ ${ }^{1}$ Department of Occupational Health Engineering, Health Sciences Research Center, School of Health, Mashhad University of Medical Sciences, Mashhad, IR Iran \\ ${ }^{*}$ Corresponding author: Seyedeh Negar Assadi, Department of Occupational Health Engineering, Health Sciences Research Center, School of Health, Mashhad University of Medical \\ Sciences, Mashhad, IR Iran. Tel:+98-9123856325, E-mail: assadin@mums.ac.ir
}

Received: July 1, 2015; Revised: July 27, 2015; Accepted: July 29, 2015

\begin{abstract}
Background: Some occupations have risk factors for chronic low back pain; clinical staff of hospitals are good examples for encountering many risk factors yet office staff encounter a few or may be at risk of unknown factors for occupational low back pain.

Objectives: The objective of this study was to compare chronic low back pain frequency and risk factors between clinical and office staff. Patients and Methods: A cross-sectional study on clinical and office staff at hospitals was done by completing a questionnaire with interviews and a checklist. Data were analyzed with the SPSS software version 16 using chi-2, T-test and regression with significance level of $\mathrm{P}<0.05$.

Results: No significant difference was observed between the two groups in terms of chronic low back pain; frequency of low back pain in clinical staff was 18\% (18 individuals) and in office staff this was $17 \%$ (17 individuals) $(\mathrm{P}<0.05)$. Chronic low back pain in the clinical group might be related to flexion and extension, twisting, pulling or pushing, carrying, handling of patients, and sitting (P value $<0.001)$, and in office staff it might be related to flexion and extension, twisting and long durations of time spent driving (P value $<0.001)$.

Conclusions: Frequency of low back pain was not significantly different between clinical and office staff. Chronic low back pain in clinical staff was related to work while in office staff it was related to some occupational and non-occupational risk factors.
\end{abstract}

Keywords: Low Back Pain; Risk Factors; Occupational Disease; Chronic

\section{Background}

Low back pain is the second cause of absenteeism after common cold and can cause disability (1). By the determination of occupational risk factors and repairing them we will able to early diagnose and prevent chronic disorders (1).

Each occupation has some different risk factors for the cause of disorders for example; health care is one of these occupations. The frequency of musculoskeletal pain in health care workers in the worlds is $30 \%$ to $70 \%(2)$. The important risk factors for low back pain are flexion, extension and bending, rotations of lumbar spine, pulling or pushing things or carrying patients more than $23 \mathrm{kgs}$ (1). Low back pain has some types and one of them is chronic low back pain with more than 12 weeks pain (3).

Omokhodion et al. studied on clinical rural hospitals in Nigeria, the staff had low back pain in about $69 \%$ of nurses , 55\% of office workers, $47 \%$ housekeeping service providers, $47 \%$ of staff with heavy work had low back pain, staff with unsuitable posture had 20\% low back pain , 20\% of staff with longtime sitting and standing had low back pain (4).

Feyer et al. in Australia demonstrated that general health questionnaire (GHQ) with high score was a risk factor for low back pain (5). Roupa et al. in Greece showed that $40 \%$ of nurses with some history of low back pain that had effects on their mood and sleep quality (6). Maul et al. in Germany demonstrated that the frequency of low back pain was common among 73to 76\% of nurses and they had recurrent low back pain more than progressive low back pain (7). Lorusso et al. in Italy found that the prevalence of low back pain in nurses were 33 to $86 \%$ and it depended on gender, physical and psychological risk factors (8). Nielsen et al. in Europe showed that there was a relationship between working in hospitals and low back pain. The prevalence of low back pain was $23.3 \%$ to 56.6\% among hospital staff( 9 ).

Plouvier et al. in France demonstrated that low back pain was related to work and driving duration (10).

Mechanical chronic low back pain is the subject of this study. Chronic low back pain lasts more than three months. It is aggravated with physical activity and it becomes better with rest and during vacations $(1,2)$.

Because of high frequency of low back pain and its importance also could be caused disability and few studies

Copyright (C) 2015, Semnan University of Medical Sciences. This is an open-access article distributed under the terms of the Creative Commons Attribution-NonCommercial 4.0 International License (http://creativecommons.org/licenses/by-nc/4.0/) which permits copy and redistribute the material just in noncommercial usages, provided the original work is properly cited. 
were done in Khorasan Razavi, this study was performed. In Iran some studies were researched about the occupational risk factors of musculoskeletal disorders (11-13).

There were a few studies in this subject about the office staff risks but there were some reports from low back pain in clinical staff group.

Because there were some preventive methods those must be done for prevention of low back pain in hospital staff such as clinical and official, and their risk factors must be found this study was done.

\section{Objectives}

The objective of this study is the comparison of low back pain frequency and its risk factors between clinical and office staff in hospitals of Mashhad there are only a few studies considering clinical staff.

\section{Patients and Methods}

\subsection{Study Setting}

The study setting was the hospitals of the city of Mashhad (10 hospitals).

\subsection{Study Design and Target Population}

This was a cross-sectional study. The population of this study was clinical and office staff working in hospitals, who were selected with simple random sampling ( $\alpha$ $=0.05, \beta=0.80, \mathrm{P} 1=40 \%$ and $\mathrm{P} 2=20 \%$ ). There were 100 people, in each group of clinical and administrative staff, from 10 hospitals. About 650 people were evaluated for having the inclusion criteria, and those who did not meet these criteria were excluded from study. The author interviewed 650 people for assessment of exclusion and inclusion criteria and then filled the questionnaire and checklist for 200 people; 100 people in the clinical and 100 people in the office staff groups.

Inclusion criteria were being a clinical or office staff with work duration of one year or more. The exclusion criteria were having had trauma out of the work environment, non-mechanical pain, inflammation and rheumatologic disorders, fever and major infection. Office staffs were studied because they did not have as many occupational risk factors and were only at risk of factors such as flexion, extension, lumbar rotation and prolonged sitting.

The two groups were matched for age, family history of low back pain and Body Mass Index (BMI). More than 90\% of clinical and office staff were females.

\subsection{Questionnaire Design}

This study was done by completing a checklist and a questionnaire, which was done by interviewing clinical and office staff. Both the checklist and the questionnaire were obtained by the quick exposure check (QEC) method. For validity and reliability of the research tool; the questionnaire was improved at the education department with related professors' opinions (about 22 faculty members), we also performed a pilot study with a correlation coefficient of $85 \%$ with a thirty-day interval between the two trials. The questionnaire of this study had questions about low back pain and its duration, and whether it is aggravated with physical activity and if it becomes better with rest and vacation $(1,2)$. Furthermore, non-occupational and occupational risk factors for chronic low back pain were included in the questionnaire (1-3).

Measurements: occupational risks from quick exposure check (QEC) tools were determined. Non occupational risks included; age, weight and height, body mass index, duration of driving, history of previous mechanical low back pain, family history, absenteeism, duration of low back pain and psychological stress. Occupational risks included; job history, number of flexions and extensions, bending, rotation in an hour, carrying, pushing, pulling more than $23 \mathrm{~kg}$ or number of times they carried a patient in one day, specially among clinical personnel, and the duration of sitting at the station during one day, specially among office staff (1-3).

\subsection{Statistical Analysis}

Data were gathered and analyzed by the SPSS software version 16 , for calculating frequencies, and means. T-test was used for quantitative variables, $\chi^{2}$ for qualitative variables and regression with $\mathrm{P}<0.05$. In the regression analysis, occupational risk factors such as the number of flexions and extensions, bending, rotation, carrying, pushing, pulling, sitting and non-occupational risk factors, such as driving, were analyzed.

\subsection{Ethical Consideration}

This study was approved by the university board, for research ethics. Oral consent was taken from participants.

\section{Results}

In this study 100 people from clinical departments (general workers, nurses and physicians) and 100 from office departments were included. The mean of age in clinical was $35.2 \pm 7.5$ years old and in office group was $33.5 \pm 6.6$ years old. No significant difference between two groups ( $\mathrm{P}=0.082$ ). There was no significant difference between the two groups in terms of the frequency of chronic low back pain; amongst clinical staff there were 18 people (18\%) and amongst office staff there were 17 people (17\%) with low back pain $(\mathrm{P}=1.000)$. According to quick exposure check results there was a low risk for musculoskeletal disorders.

Comparison of the general information of clinical and office staff revealed that there was no significant difference between the two groups in terms of gender; clinical participants included 92 females (92\%) and eight males (8\%), and office staff included 93 females (93\%) and seven 
males $(7 \%)(P=1.000)$.

There was no significant difference between the two groups in terms of smoking; amongst clinical participants 98 (98\%) were non-smokers and amongst office staff 99 (99\%) were non-smokers $(\mathrm{P}=0.561)$.

Regarding personal risk factors, there was no significant difference between the two groups in terms of sports training; in clinical participants eleven (11\%) individuals and in office staff eight (8\%) cases were involved in sport activities $(\mathrm{P}=0.631)$.

There was no significant difference between the two groups in terms of driving history; amongst clinical staff eleven (11\%) and amongst office staff fourteen (14\%) individuals had a history of driving $(P=0.834$. $)$

There was no significant difference between the two groups in terms of psychological history; in the clinical group one (1\%) and in the office group two (2\%) individuals had a psychological history $(\mathrm{P}=1.000)$. Other risk factors are demonstrated in Table 1.

The comparison of general information of clinical and office staff with chronic low back pain, indicated no significant difference between the two groups in terms of gender; amongst clinical staff there were 16 (88.9\%) females and two (11.1\%) males, and among office staff there were 15 (88.23\%) females and two (11.76\%) males $(\mathrm{P}=1.000)$.

There was no significant difference between the two groups in terms of smoking; in clinical staff there were
$17(94.44 \%)$ and in office staff there were 16 (94.11\%) nonsmokers $(\mathrm{P}=1.000)$.

Regarding personal risk factors, there was no significant difference between the two groups in terms of sports training; in clinical staff there was one (5.5\%) and in office staff there was one (5.9\%) individual involved in sport activities $(\mathrm{P}=1.000)$. There was no significant difference between the two groups in terms of driving history; amongst clinical staff there were two (11.1\%) and amongst office staff there were eight (47.05\%) individuals who had driving history $(\mathrm{P}=0.019)$. None of them had psychological disorders.

There was no significant difference between the two groups in terms of history of low back pain; amongst clinical staff seven (38.9\%) and amongst office staff five (29.42\%) individuals had a history of low back pain ( $\mathrm{P}=$ 0.555). Other risk factors are presented in Table 2.

\subsection{Regression Analysis}

Regression analysis demonstrated that low back pain of the clinical group might be related to flexion and extension, rotation, pull or push, and carrying heavy items. Regarding the number of patients handling and sitting $(\mathrm{P}<0.001)$, who were office workers with chronic low back pain, it could be suggested that this pain might be related to flexion and extension, rotation and driving duration $(\mathrm{P}<0.001)$ (Table 3$)$.

Table 1. Comparison of Risk Factors Between Clinical and Office Workers $(\mathrm{P}<0.05)$

\begin{tabular}{|c|c|c|c|c|}
\hline \multirow[t]{2}{*}{ Variable } & \multicolumn{4}{|c|}{ Group } \\
\hline & Clinical Worker $^{\mathrm{a}}$ & office Worker $^{\mathrm{a}}$ & t-Test & PValue \\
\hline Age, y & $35.29 \pm 7.50$ & $35.4 \pm 6.67$ & 1.750 & 0.082 \\
\hline Body mass index, $\mathrm{kg} / \mathrm{m}^{2}$ & $26.12 \pm 3.43$ & $25.53 \pm 3.45$ & 1.206 & 0.229 \\
\hline Work duration, $\mathbf{y}$ & $10.38 \pm 5.20$ & $9.62 \pm 5.17$ & 1.035 & 0.302 \\
\hline Driving duration, hours in a day & $0.13 \pm 0.35$ & $0.15 \pm 0.40$ & -0.465 & 0.643 \\
\hline Flexion, Extension in an hour & $4.91 \pm 8.35$ & $3.96 \pm 7.92$ & 0.410 & 0.410 \\
\hline Rotation in an hour & $2.79 \pm 5.42$ & $2.70 \pm 5.62$ & 0.115 & 0.908 \\
\hline Pull/Push in an hour & $0.65 \pm 1.67$ & $0.16 \pm 0.61$ & 2.742 & 0.007 \\
\hline Carrying in a day & $2.24 \pm 1.65$ & 0 & 13.558 & $<0.001$ \\
\hline Patient handling in a day & $2.60 \pm 1.56$ & 0 & 16.630 & $<0.001$ \\
\hline Sitting hours in a day & $5.67 \pm 0.57$ & $6.92 \pm 0.35$ & -18.560 & $<0.001$ \\
\hline
\end{tabular}

\footnotetext{
a Data are presented as mean \pm SD.
} 
Assadi SN

\begin{tabular}{|c|c|c|c|c|}
\hline \multirow[t]{2}{*}{ Variable } & \multicolumn{4}{|c|}{ Group } \\
\hline & Clinical Worker $^{\mathrm{a}}$ & Office Worker ${ }^{a}$ & t-Test & P Value \\
\hline Age, $y$ & $37.77 \pm 8.56$ & $34.88 \pm 8.34$ & 1.413 & 0.319 \\
\hline Body mass index kg/m² & $26.61 \pm 3.90$ & $24.89 \pm 3.65$ & 0.002 & 0.163 \\
\hline Work duration, Years & $12.66 \pm 5.91$ & $10.58 \pm 7.09$ & 0.607 & 0.352 \\
\hline Driving duration, hours in a day & $0.11 \pm 0.32$ & $0.55 \pm 0.65$ & 1.245 & 0.019 \\
\hline Flexion, Extension in an hour & $21.50 \pm 3.74$ & $20.95 \pm 1.02$ & 2.113 & 0.557 \\
\hline Rotation in an hour & $13.94 \pm 2.55$ & $14.70 \pm 2.28$ & 0.637 & 0.360 \\
\hline Pull/Push in an hour & $3.16 \pm 2.70$ & $0.11 \pm 0.48$ & -0.834 & $<0.001$ \\
\hline Carrying in a day & $4.22 \pm 1.11$ & 0 & 11.596 & $<0.001$ \\
\hline Patient handling in a day & $4.33 \pm 0.90$ & 0 & 14.210 & $<0.001$ \\
\hline Sitting hours in a day & $4.88 \pm 0.58$ & $7.00 \pm 0$ & -17.293 & $<0.001$ \\
\hline Low back pain duration, months in one year & $7.11 \pm 2.02$ & $6.82 \pm 0.63$ & 0.559 & 0.573 \\
\hline Absenteeism time, days in a month & $4.11 \pm 2.60$ & $4.48 \pm 3.08$ & -0.373 & 0.712 \\
\hline
\end{tabular}

a Data are presented as mean \pm SD.

Table 3. Regression Analysis for Assessment of the Relationship Between Each of the Risk Factors and Low Back Pain in the Two Groups With Significance Level of $r<0.05$

\begin{tabular}{lcc}
\hline Risk Factor & \multicolumn{2}{c}{ Regression Analysis, r Value } \\
\cline { 2 - 3 } & Significance Clinical & Significance Office \\
\hline Flexion, bending per hour & $<0.001$ & $<0.001$ \\
\hline Rotation per hour & $<0.001$ & $<0.001$ \\
\hline Push or pull per day & $<0.001$ & 0.754 \\
\hline Carrying per day & $<0.001$ & - \\
\hline Patient handling per day & $<0.001$ & 0.303 \\
\hline Sitting hours per day & $<0.001$ & 0.359 \\
\hline Work duration years & 0.039 & $<0.001$ \\
\hline Driving duration in hours per day & 0.805 & - \\
\hline
\end{tabular}

\section{Discussion}

According to the results the frequency of low back pain was $18 \%$ amongst clinical and $17 \%$ amongst office workers; there was no significant differences between the two groups. This means that the frequency of chronic low back pain between the two groups was similar. Amongst clinical staff, low back pain might be related to flexion, extension, twisting or rotation, pulling or pushing, carrying, sitting and work duration $(\mathrm{P}<0.001)$. However, amongst office staff low back pain might be related to flexion, extension, twisting or rotation, and driving duration
$(\mathrm{P}<0.001)$ (Table 3). There were no differences between the two groups regarding the frequencies of smoking, psychological history, gender and sport activities; these items were non-occupational risk factors. This means that chronic low back pain was related to occupational risk factors in clinical staff. Chronic low back pain was related to occupational and only one non-occupational risk factor (driving) in office workers. In other studies the frequency of low back pain among hospital staff was 19 to $70 \%(1-3)$. Although in the study of Omokhodion et al. 
it was demonstrated that $69 \%$ of nurses and $55 \%$ of office workers had low back pain (4), in the current study, staff were at a better status, which was related to good occupational health in hospitals. They had pre placement examination in the recent years and the staffs were younger.

Nielsen et al. showed the relation between low back pain and working at hospitals (9). Lorusso et al. showed that frequency of low back pain in nurses were 33\% to $86 \%$ and it depended on gender, physical and psychological factors (8).

In this study, low back pain in hospital staff had not significant difference between men and women, many of our participants were women.

In this study one of the clinical staff had a psychological disorder and occupational stress yet this did not result in a significant difference between the groups. Feyer et al. demonstrated that a high score for the general health questionnaire (GHQ) was related to low back pain (5). In this study the population had a good mental health status. Similar to previous studies, low back pain was related to some physical or mechanical risk factors.

Omokhodion et al. demonstrated that low back pain was related to pull or push, carrying items and patient handling in clinical sittings with a significant difference (4). In this study after regression analysis among clinical staff, it was demonstrated that low back pain might have been related to flexion, extension, twisting or rotation, pulling or pushing, carrying, sitting and work duration; while in office staff low back pain might have been related to flexion, extension, twisting or rotation and driving duration. Office staff spent more time sitting yet their low back pain was more related to some non-occupational risk factors such as driving. Similar to the current study, Plouvier et al. found a relationship between low back pain and work duration, flexion, extension, rotation and driving (10). The duration of low back pain was longer in clinical and the duration of absenteeism was longer among office staff, yet these differences were not significant. These results were similar to previous studies (14-16).

Other studies showed that early therapy, short resting time, home exercises and return to light work could help prevent chronic low back pain and disability $(17,18)$.

Clinical jobs such as nursing have greater occupational risk factors for low back pain such as, flexion, extension, twisting or rotation, pulling or pushing, carrying, handling of patients and specific helping behaviors. Among office staff, duration of driving was more effective on chronic low back pain than sitting for a long time, since during driving the vibration of the car is translated to the lumbar spine.

Musculoskeletal disorders were the most common disorders in some occupations and industries (19-22). Such industries must implement preventive methods for related disorders. Pre-placement programs and periodic examinations should pay attention to the person's musculoskeletal system.
In this study there was no exact job analysis and the data was gathered from the staff's memory, however some previous studies had performed an exact job analysis $(12,13)$. Unfortunately the number of people that could participate after the application of the exclusion criteria was low especially the number of males. It seems that a complementary study can be helpful. Future studies should perform exact job analyses and determine further occupational risk factors for clinical personnel yet they should also pay more attention to non-occupational risk factors such as driving for office workers.

In clinical staff low back pain might be related to occupational risk factors yet among office workers this pain might be related to occupational and non-occupational risk factors such as duration of driving. Duration of driving was more effective on low back pain than sitting for a long time. Future studies should investigate risk factors for other health care workers.

\section{Acknowledgements}

The author would like to thank the Vice Chancellor of Research of Mashhad University of Medical Sciences for all their supports.

\section{Funding/Support}

Mashhad University of Medical Sciences, Mashhad, IR Iran.

\section{References}

1. Evanoff BA. Back and lower extremity disorders. In: Rosenstock KL, editor. Textbook of Clinical Occupational and Environmental Medicine. Elsevier; 2005. pp. 527-32.

2. Heibert R, Weiser S, Campello M, Nordin M. Nonspecific low back pain. In: Rom WN, editor. Environmental and occupational medicine. lippincott Williams and wilkins; 2007. pp. 924-36.

3. Hoaglund FT. Musculoskeletal injuries. In: Ladou J, editor. Current Occupational and Environmental Medicine. McGraw - Hill; 2004. pp. 43-68.

4. Omokhodion FO, Umar US, Ogunnowo BE. Prevalence of low back pain among staff in a rural hospital in Nigeria. Occup Med. 2000;50(2):107-10.

5. Feyer AM, Herbison P, Williamson AM, de Silva I, Mandryk J, Hendrie L, et al. The role of physical and psychological factors in occupational low back pain: a prospective cohort study. Occup Environ Med. 2000;57(2):116-20.

6. Roupa Z, Vassilopoulos A, Sotiropoulou P, Makrinika E, Noula M Faros E, et al. The problem of lower back pain in nursing staff and its effect on human activity. Health Sci J. 2008;2(4):219-25.

7. Maul I, Laubli T, Klipstein A, Krueger H. Course of low back pain among nurses: a longitudinal study across eight years. Occup Environ Med.2003;60(7):497-503.

8. Lorusso A, Bruno S, L'Abbate N. A review of low back pain and musculoskeletal disorders among Italian nursing personnel. Ind Health. 2007;45(5):637-44

9. Nabe-Nielsen K, Fallentin N, Christensen KB, Jensen JN, Diderichsen F. Comparison of two self-reported measures of physical work demands in hospital personnel: A cross-sectional study. BMC Musculoskelet Disord. 2008;9(1):61.

10. Plouvier S, Renahy E, Chastang JF, Bonenfant S, Leclerc A. Biomechanical strains and low back disorders: quantifying the effects of the number of years of exposure on various types of pain. Occup Environ Med. 2008;65(4):268-74.

11. Arsalani N, Fallahi-Khoshknab M, Josephson M, Lagerstrom M. 
Musculoskeletal disorders and working conditions among Iranian nursing personnel. Int J Occup Saf Ergon. 2014;20(4):671-80.

12. Motamedzade M, Ashuri MR, Golmohammadi R, Mahjub $\mathrm{H}$. Comparison of ergonomic risk assessment outputs from rapid entire body assessment and quick exposure check in an engine oil company. J Res Health Sci. 2011;11(1):26-32.

13. Choobineh AR, Daneshmandi H, Aghabeigi M, Haghayegh A. Prevalence of musculoskeletal symptoms among employees of Iranian petrochemical industries: October 2009 to December 2012. Int J Occup Environ Med. 2013;4(4):195-204.

14. Brattig B, Schablon A, Nienhaus A, Peters C. Occupational accident and disease claims, work-related stress and job satisfaction of physiotherapists. J Occup Med Toxicol. 2014;9(1):36.

15. Bonfiglioli R, Di Lello M, Violante FS. [Health surveillance and suitability: the role of the company physician in maintaining work ability]. G Ital Med Lav Ergon. 2014;36(4):267-71.

16. Leao AL, Barbosa-Branco A, Rassi Neto E, Ribeiro CA, Turchi MD. Sickness absence in a municipal public service of Goiania, Brazil. Rev Bras Epidemiol. 2015;18(1):262-77.

17. Yasobant S, Rajkumar P. Work-related musculoskeletal disorders among health care professionals: A cross-sectional assessment of risk factors in a tertiary hospital, India. Indian J Occup Environ Med. 2014;18(2):75-81.

18. Bernal D, Campos-Serna J, Tobias A, Vargas-Prada S, Benavides FG Serra C. Work-related psychosocial risk factors and musculoskeletal disorders in hospital nurses and nursing aides: a systematic review and meta-analysis. Int J Nurs Stud. 2015;52(2):635-48.

19. Warren N, Dussetschleger J, Punnett L, Cherniack MG. Musculoskeletal disorder symptoms in correction officers: why do they increase rapidly with job tenure? Hum Factors. 2015;57(2):262-75.

20. Sharma PK, Ganguly E. Morbidity profile of long distance truck drivers in Hyderabad city, India. J Dr NTR Univ Health Sci. 2014;3(4):234-7.

21. Telaprolu N, Anne SD. Physical and psychological work demands as potential risk factors for musculoskeletal disorders among workers in weaving operations. Indian J Occup Environ Med. 2014;18(3):129-34.

22. Dabholkar TA, Nakhawa P, Yardi S. Common musculoskeletal problem experienced by fishing industry workers. Indian J Occup Environ Med. 2014;18(2):48-51. 